\title{
Afatinib inhibits proliferation and invasion and promotes apoptosis of the T24 bladder cancer cell line
}

\author{
YUNHUA TANG $^{1}$, XIANGYANG ZHANG ${ }^{1}$, FAN QI $^{1}$, MINGFENG CHEN $^{1}$, YUAN LI $^{1}$, \\ LONGFEI LIU ${ }^{1}$, WEI HE ${ }^{1}$, ZHUO $\mathrm{LI}^{2}$ and XIONGBING ZU ${ }^{1}$ \\ ${ }^{1}$ Department of Urology, Xiangya Hospital, Central South University; ${ }^{2}$ Department of Urology, \\ Hunan Provincial People's Hospital, Changsha, Hunan 410008, P.R. China
}

Received July 19, 2014; Accepted January 30, 2015

DOI: $10.3892 / \mathrm{etm} .2015 .2314$

\begin{abstract}
Afatinib is a highly selective, irreversible inhibitor of the epidermal growth factor receptor (EGFR) and human EGFR 2 (HER-2). Although preclinical and clinical studies have indicated that afatinib has antitumor activity and clinical efficacy in non-small cell lung carcinoma, head and neck squamous cell carcinoma and breast cancer, there are few studies investigating its inhibitory effect on human bladder carcinoma cells. In this study, the antitumor effect of afatinib was investigated on the T24 bladder cancer cell line. The T24 bladder cancer cell line was treated with afatinib at various concentrations $(0,1,5,10$ and $20 \mu \mathrm{mol} / \mathrm{l})$. MTT assay was used to estimate the proliferation of the T24 cells; flow cytometric analysis was used to estimate the effect of afatinib on T24 cell apoptosis; cell invasion ability was assessed by a Transwell invasion assay; and western blot analysis was used to detect the expression of Bcl-2, Bax, Akt, extracellular-signal-regulated kinase (ERK)1/2, matrix metalloproteinase (MMP)-2 and MMP-9. The MTT assay demonstrated that afatinib inhibited the proliferation of T24 cells in a dose- and time-dependent manner. Flow cytometric analysis revealed that the cell apoptosis rate increased as the concentration of afatinib increased. The cell invasion assay indicated that afatinib treatment significantly inhibited the invasive behavior of T24 cells in a dose-dependent manner. Western blot analysis showed that with increasing afatinib concentrations, Bcl-2, phosphorylated (p)-ERK1/2, p-Akt, MMP-2 and MMP-9 expression levels were significantly decreased, whereas total
\end{abstract}

Correspondence to: Professor Xiongbing $\mathrm{Zu}$, Department of Urology, Xiangya Hospital, Central South University, 87 Xiangya Road, Changsha, Hunan 410008, P.R. China

E-mail: tang_yunhua@163.com

Dr Zhuo Li, Department of Urology, Hunan Provincial People's Hospital, 61 West Liberation Road, Changsha, Hunan 410008, P.R. China

E-mail: 379997347@qq.com

Key words: afatinib, proliferation, invasion, apoptosis, bladder cancer
(t)-ERK1/2 and t-Akt expression levels remained basically unchanged, and Bax expression levels were greatly increased. The results indicate that afatinib inhibits the proliferation and invasion of T24 cells in vitro and induces the apoptosis of these cells by inhibiting the EGFR signaling network.

\section{Introduction}

Bladder cancer is the second most common tumor of the urogenital system in the USA, with $70 \%$ of patients diagnosed with superficial tumors and $30 \%$ presenting with muscle-invasive disease (1); 386,300 new cases of bladder carcinoma are diagnosed around the world every year, accounting for almost 150,200 mortalities (2). Currently, although surgical therapies, such as transurethral electroresection of bladder tumors used mainly to treat superficial bladder cancer and radical cystectomy used to muscle-invasive bladder cancer, combined with adjuvant chemotherapy after surgery have made great progress in the treatment of bladder cancer, the rate of recurrence remains high (3). Moreover, chemotherapy has a high incidence of side-effects. Therefore, the research and development of highly efficient and minimally toxic new drugs is sorely required.

The human epidermal growth factor receptor (EGFR) family comprises four members: EGFR, human EGFR (HER)-2, HER-3 and HER-4 (4), which play crucial roles in cell proliferation and survival via activation of the EGFR signaling network (5). The overexpression of EGFR and HER-2 is associated with higher EGFR pathway signaling activity, increased proliferation of cancer cells and reduced apoptosis (6). Afatinib is the EGFR family blocker with the highest potential, and is a highly selective, irreversible inhibitor of EGFR and HER-2 (7). Although preclinical and clinical studies have indicated that afatinib has antitumor activity and clinical efficacy in non-small cell lung carcinoma, head and neck squamous cell carcinoma and breast cancer (8), there are few studies investigating its inhibitory effect on human bladder carcinoma cells (9-11). Based on the fact that it has been demonstrated that the overexpression of EGFR and HER-2 is present in bladder carcinoma (12-14), it is hypothesized that afatinib may be feasible and effective to use in the treatment of bladder cancer by targeting both EGFR and HER-2. 
In this study, the inhibitory effects of afatinib were investigated on the T24 bladder cancer cell line. Whether afatinib inhibits proliferation and invasion and promotes apoptosis of the T24 bladder cancer cell line by inhibiting the EGFR signaling network was also investigated.

\section{Materials and methods}

Cell culture. The T24 human bladder cancer cell line was obtained from Shanghai Institute of Biochemistry and Cellular Biology Chinese Academy of Sciences (Shanghai, China), and was cultured in Dulbecco's modified Eagle's medium (DMEM; Gibco Life Technologies, Carlsbad, CA, USA) with $10 \%$ fetal bovine serum, $100 \mathrm{U} / \mathrm{ml}$ penicillin and $100 \mathrm{U} / \mathrm{ml}$ streptomycin in a humidified atmosphere with $5 \% \mathrm{CO}_{2}$ at $37^{\circ} \mathrm{C}$.

MTT assay. The MTT assay was used to estimate the proliferation of the T24 cells. The cell concentration was adjusted to $5 \times 10^{4}$ cells $/ \mathrm{ml}$ and cells were grown in a 96 -well plate, at $190 \mu \mathrm{l} /$ well. After $24 \mathrm{~h}$ incubation at $37^{\circ} \mathrm{C}$ in a $5 \% \mathrm{CO}_{2}$ incubator, the T24 cells were treated with afatinib at various concentrations $(0,1,5,10$ and $20 \mu \mathrm{mol} / \mathrm{l})$ for 12,24 and $48 \mathrm{~h}$. At each time-point, $20 \mu 15 \mathrm{mg} / \mathrm{ml} \mathrm{MTT}$ was added to each well, and cells were incubated for an additional $4 \mathrm{~h}$. Then, the supernatant was removed, and $150 \mu \mathrm{l}$ DMSO was added to every well. The absorbance was measured at $490 \mathrm{~nm}$. Cell survival rate $(\%)=$ (treatment group absorbance/control group absorbance $\mathrm{x}$ 100). Each assay was repeated three times.

Flow cytometric analysis of apoptosis. Following treatment with various concentrations of afatinib for $24 \mathrm{~h}$, cells were harvested by trypsinization and washed with phosphate-buffered saline three times, followed by resuspending in binding buffer at a concentration of $2 \times 10^{5}$ cells $/ \mathrm{ml}$. Subsequently, $5 \mu \mathrm{l}$ annexin-V-fluorescein isothiocyanate (FITC) and $5 \mu \mathrm{l}$ propidium iodide (PI) were added to the suspension and the cells were incubated at room temperature in the dark for $10 \mathrm{~min}$. The apoptotic cells were then measured on a FACScalibur Flow Cytometer (BD Biosciences, San Jose, CA, USA).

Invasion assay. Cell invasion ability was assessed using a Transwell chamber (Corning Costar; Corning Incorporated Tewksbury, MA, USA) with an $8.0-\mu \mathrm{m}$ pore polycarbonate membrane filter that was precoated with Matrigel (BD Biosciences) diluted at the ratio of 1:5. Cells treated with various concentrations of afatinib were harvested and seeded in the upper chamber at a density of $5 \times 10^{5}$ cells $/ \mathrm{ml}$ with serum-free DMEM, and the lower chambers were filled with culture DMEM supplemented with $10 \%$ fetal bovine serum. After reculturing at $37^{\circ} \mathrm{C}$ in a $5 \% \mathrm{CO}_{2}$ atmosphere for $24 \mathrm{~h}$, the Transwell chambers were inverted and stained with hematoxylin. The cell invasion ability was assessed by counting the number of cells that had migrated to the lower side of the membrane. Cells in five visual fields (magnification, $\mathrm{x} 400$ ) selected randomly were counted in each Transwell chamber.

Western blot analysis. Cells were harvested after $24 \mathrm{~h}$ of treatment with afatinib at various concentrations $(0,1,5,10$ and $20 \mu \mathrm{mol} / \mathrm{l})$. Proteins from each sample were separated using $10 \%$ sodium dodecyl sulfate polyacrylamide

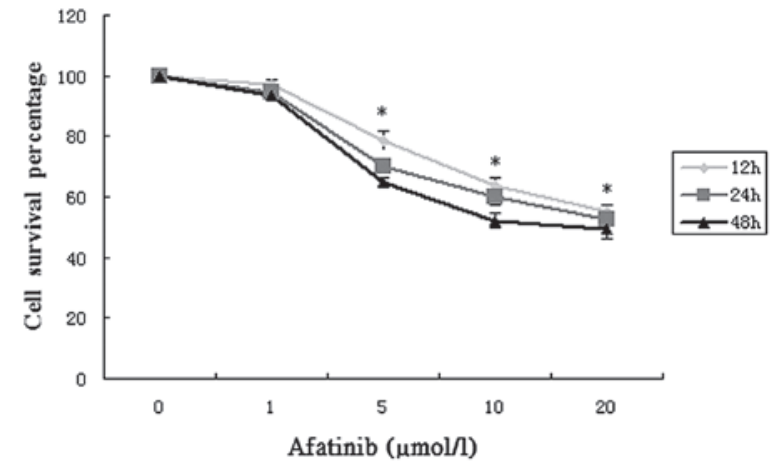

Figure 1. Afatinib inhibits the proliferation of T24 cells. Cell proliferation and viability were determined by an MTT assay. Cell viability was observed with afatinib treatment at various concentrations $(0,1,5,10$ and $20 \mu \mathrm{mol} / \mathrm{l})$ for 12,24 and $48 \mathrm{~h}$. Data are presented as mean \pm standard deviation $(n=3)$. ${ }^{*} \mathrm{P}<0.05$ compared with control $(0 \mu \mathrm{mol} / 1$ afatinib).

gel electrophoresis (SDS-PAGE) and transferred to a nitrocellulose membrane. Then, the proteins were incubated with primary antibody in blocking buffer, followed by incubation with secondary antibody, for $1 \mathrm{~h}$ each at room temperature. The primary antibodies and dilutions used were as follows: Rabbit Bcl-2 monoclonal antibody, rabbit Bax monoclonal antibody, rabbit phosphorylated (p)-Akt polyclonal antibody, rabbit t-Akt polyclonal antibody, rabbit p-extracellular-signal-regulated kinase (ERK) 1/2 monoclonal antibody, rabbit total (t)-ERK1/2 monoclonal antibody, rabbit matrix metalloproteinase (MMP)-2 polyclonal antibody, rabbit MMP-9 polyclonal antibody and rabbit $\beta$-actin polyclonal antibody (all Wuhan Boster Biological Technology, Ltd., Wuhan, China; 1:1,000). The secondary antibodies were horseradish peroxidase-conjugated goat anti-rabbit IgG (Wuhan Boster Biological Technology, Ltd.; 1:10,000). $\beta$-actin was examined on the same membrane and used as a loading control. The relative levels of the target protein were represented as the optical density (OD).

Statistical analysis. All data were processed using the Statistical Package for Social Sciences (SPSS for Windows, version 17.0; SPSS, Inc., Chicago, IL, USA); monofactorial analysis of variance was used for analysis. Data are represented as the mean \pm standard deviation. A P-value of $<0.05$ is considered to indicate a statistically significant difference.

\section{Results}

Afatinib inhibits the proliferation of T24 cells. Using an MTT assay, the cytotoxicity of afatinib in T24 cells was evaluated and is shown in Fig. 1. When the treatment concentration was $1 \mu \mathrm{mol} / 1$, the viability of the cells changed very little. With increases in the treatment time and concentration, an evident reduction in cell viability occurred, particularly at concentrations of $5-20 \mu \mathrm{mol} / 1$. These data indicate that afatinib exerts a significant inhibitory effect on T24 cells and that the inhibition of cell viability by afatinib was dose- and time-dependent.

Afatinib induces apoptosis in T24 cells. To examine whether afatinib was able to induce apoptosis in T24 cells, flow cytometry was used to assess the cell apoptosis rate. As shown in Fig. 2, when compared with the untreated control, 
A

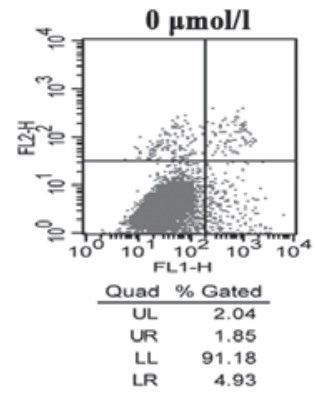

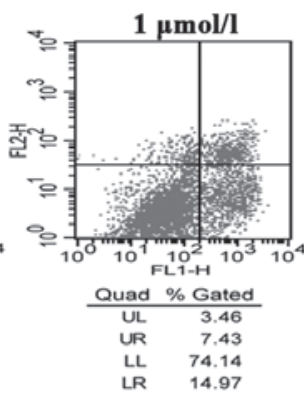
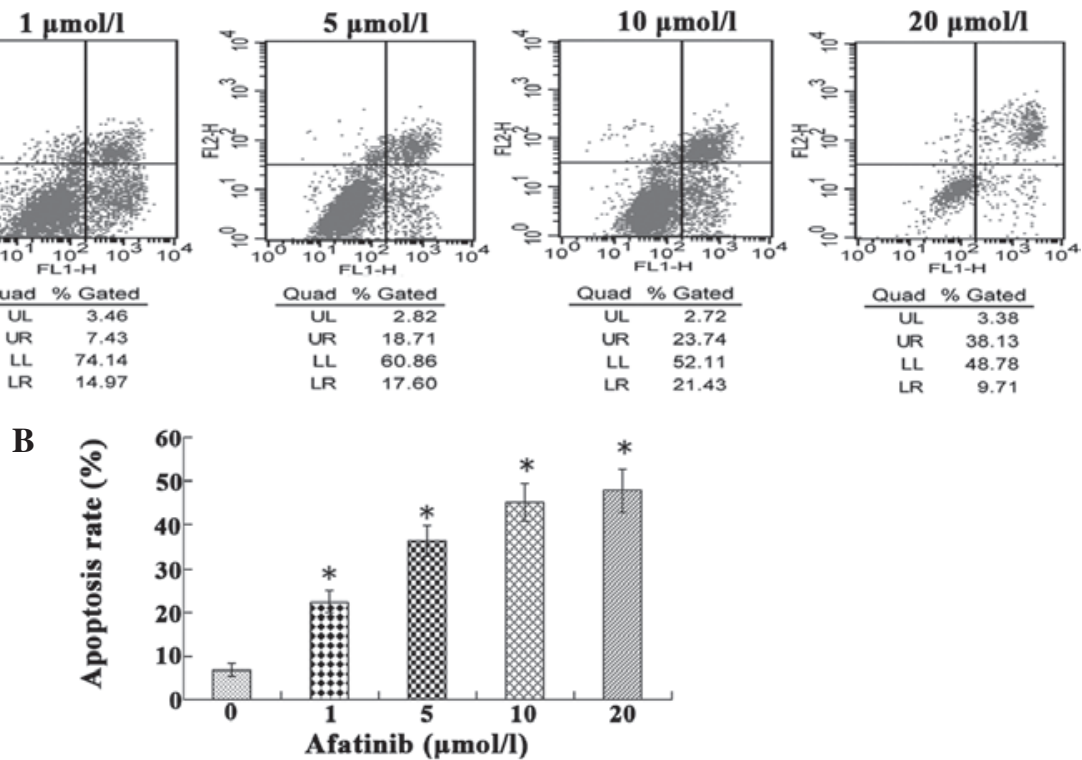

Figure 2. Afatinib induces apoptosis in T24 cells. (A) T24 cells treated with various concentrations of afatinib were double-stained with annexin V and propidium iodide and analyzed by flow cytometry. The gate setting distinguished between living [lower left (LL)], necrotic [upper left (UL)], early apoptotic [lower right (LR)] and late apoptotic [upper right (UR)] cells. (B) Quantitative data indicated that increasing the afatinib concentration led to dose-dependent apoptosis in T24 cells. Data are presented as mean \pm standard deviation $(\mathrm{n}=3) .{ }^{*} \mathrm{P}<0.05$ compared with control $(0 \mu \mathrm{mol} / 1 \mathrm{afatinib})$.

A

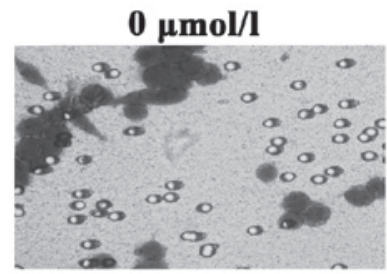

$1 \mu \mathrm{mol} / \mathrm{l}$

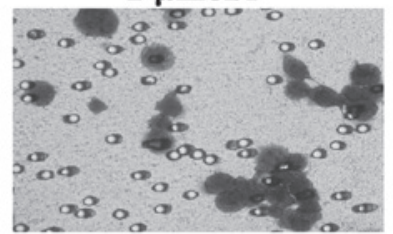

$5 \mu \mathrm{mol} / \mathrm{l}$

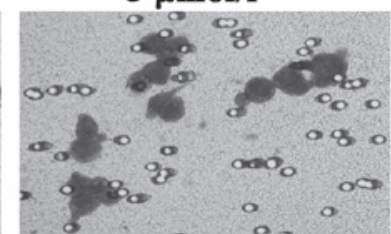

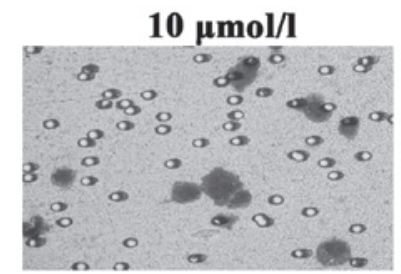

$20 \mu \mathrm{mol} / \mathrm{l}$

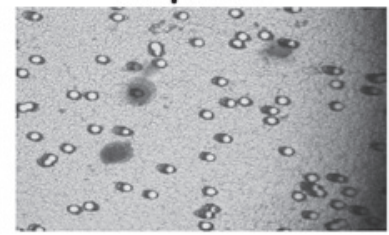

B

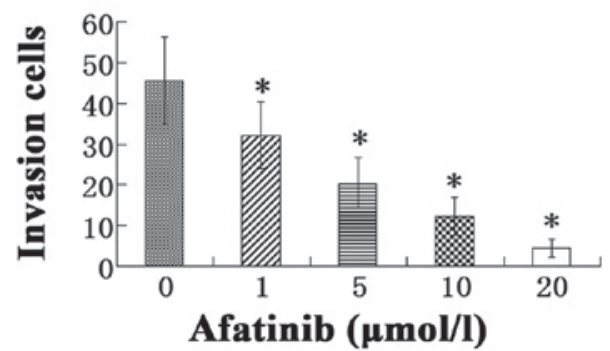

Figure 3. Effect of afatinib on T24 cell invasion. Cells treated with 0-20 $\mu \mathrm{mol} / 1$ afatinib were induced to invade through Matrigel-coated Transwell membranes. (A) There was a gradual reduction in the number of T24 cells that penetrated the Transwell chamber as the concentration of afatinib increased (magnification, $\mathrm{x} 400)$. (B) Quantitation of the cells that penetrated the membrane. Data are presented as the mean \pm standard deviation ( $\mathrm{n}=3)$. ${ }^{*} \mathrm{P}<0.05 \mathrm{vs}$. control $(0 \mu \mathrm{mol} / 1$ afatinib).

afatinib treatment resulted in apoptosis. When T24 cells were treated with afatinib for $24 \mathrm{~h}$, it was observed that increasing the concentration of afatinib from 1 to $10 \mu \mathrm{mol} / 1$ increased the proportion of early apoptotic cells from 14.97 to $21.43 \%$, respectively. However, increasing the concentration of afatinib to $20 \mu \mathrm{mol} / 1$ resulted in a reduction in the proportion of early apoptotic cells from 21.43 (at $10 \mu \mathrm{mol} / \mathrm{l}$ ) to $9.71 \%$. Between
1 and $20 \mu \mathrm{mol} / 1$, the proportion of late apoptotic cells increased from 7.43 to $38.13 \%$ in a dose-dependent manner.

Afatinib inhibits the invasiveness of T24 cells. The Transwell cell invasion assay indicated that afatinib treatment significantly inhibited the invasive behavior of T24 cells in a dose-dependent manner $(\mathrm{P}<0.05)$. The number of invasive 


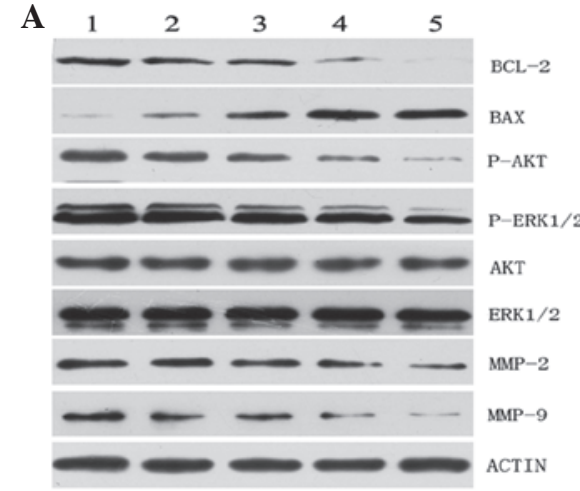

C

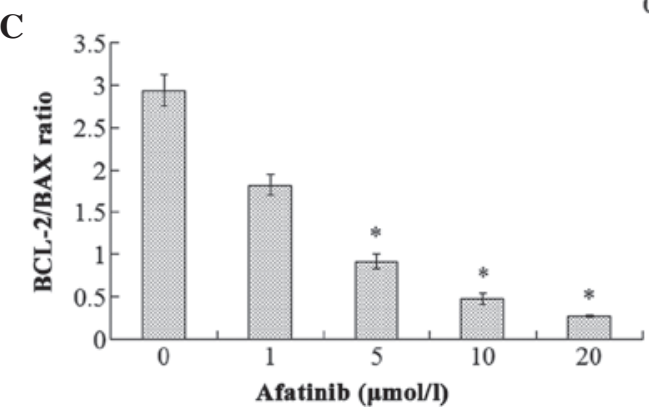

B

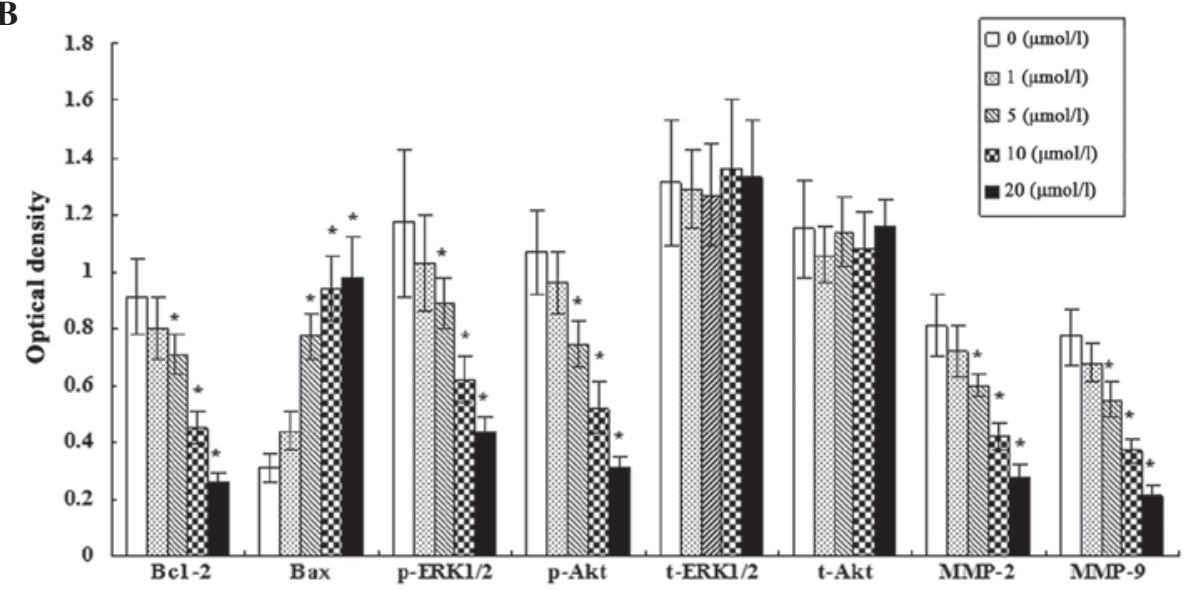

Figure 4. Expression of proteins in cells treated with different concentrations of afatinib for $24 \mathrm{~h}$ was analyzed by western blotting. (A) Bcl-2, Bax, Akt, ERK1/2, MMP-2 and MMP-9 expression in T24 cells was measured by immunoblotting. Lanes 1-5 represent different concentrations of afatinib; lane 1, $0 \mu \mathrm{mol} / 1$; lane 2, $1 \mu \mathrm{mol} / 1$; lane 3, $5 \mu \mathrm{mol} / 1$; lane 4, $10 \mu \mathrm{mol} / 1$; and lane $520 \mu \mathrm{mol} / 1$. (B) Exhibits the quantitation of tumor malignancy-related proteins; the relative protein levels were normalized to $\beta$-actin for comparison. (C) Bcl-2 and Bax expression levels were normalized to $\beta$-actin and are presented as the $\mathrm{Bax} / \mathrm{Bcl}-2$ ratio (mean \pm standard deviation). The data shown here are from a representative experiment repeated three times. ${ }^{*} \mathrm{P}<0.05$ compared with the control (0 $\mu \mathrm{mol} / 1$ afatinib) group. ERK, extracellular-signal-regulated kinase; MMP, matrix metalloproteinase.

cells in the afatinib-treated groups was observed to be gradually reduced as the concentration of afatinib was increased from 1 to $20 \mu \mathrm{mol} / \mathrm{l}$ (Fig. 3).

Effects of afatinib on the expression of proteins associated with tumor malignancy. To further investigate the probable mechanism of the afatinib-mediated biological behavior, the levels of Bcl-2, Bax, Akt, ERK1/2, MMP-2 and MMP-9 proteins were determined by western blotting. It was observed that with increasing afatinib concentration, Bcl-2, p-ERK1/2, p-Akt, MMP-2 and MMP-9 expression levels were significantly decreased, whereas t-ERK1/2 and t-Akt expression levels remained essentially unchanged, and Bax expression levels were greatly increased. In addition, the ratio of Bcl-2/Bax decreased evidently with increasing afatinib concentration $(\mathrm{P}<0.05$; Fig. 4$)$.

\section{Discussion}

The present study investigated the effect on bladder cancer cells of afatinib, which is currently being evaluated for use in the treatment of various types of cancer. The biological behavior of afatinib against the T24 bladder cancer cell line was confirmed to involve the inhibition of proliferation and invasion, the induction of apoptosis and suppression of the phosphoinositide-3-kinase (PI3K)/Akt and mitogen-activated protein kinase (MAPK)/ERK pathways.

Initially, the anti-proliferative effect of afatinib on T24 human bladder cancer cells was investigated at various concentrations $(0,1,5,10$ and $20 \mu \mathrm{mol} / \mathrm{l})$ and exposure times
(12, 24 and $48 \mathrm{~h})$. The results indicated that afatinib exerted a significant inhibitory effect on T24 cell proliferation, and that the inhibition of cell viability by afatinib was dose- and time-dependent.

Apoptosis is an essential physiological process in the induction of cell death (15). Inhibition of apoptosis is a characteristic of tumorigenesis. To confirm whether afatinib promotes T24 cell apoptosis, flow cytometry was used to assess the cell apoptosis rate, and it was found that the cell apoptosis rate increased as the concentration of afatinib increased. The association between afatinib and the Bcl-2 protein family was further investigated. The Bcl-2 protein family comprises pro-apoptotic (Bax) and anti-apoptotic ( $\mathrm{Bcl}-2)$ proteins that modulate permeabilization of the mitochondrial outer membrane and caspase activation in the control of apoptosis (16). The present study indicates that afatinib treatment upregulates the pro-apoptotic protein Bax and downregulates the anti-apoptotic protein $\mathrm{Bcl}-2$. In additional, it has been indicated that the ratio of $\mathrm{Bcl}-2 / \mathrm{Bax}$ protein expression plays a pivotal role in activating apoptotic signals (17). Therefore, the ratio of $\mathrm{Bcl}-2 / \mathrm{Bax}$ was examined; it clearly decreased as the concentration of afatinib increased, suggesting that the occurrence of T24 cell apoptosis is associated with the involvement of Bcl-2 family proteins. These results indicate that afatinib induces apoptosis in T24 bladder cancer cells.

Metastasis is the most lethal behavior of cancer, and invasion is a crucial and characteristic process of cancer metastasis. The present invasion assay demonstrated that afatinib treatment significantly inhibited the invasive behavior of T24 cells in a dose-dependent manner. The method by 
which afatinib inhibits the invasion of T24 bladder cancer cells requires consideration. The overexpression of MMPs leads to the degradation of extracellular matrix, which is essential for metastasis (18). Furthermore, extracellular matrix degradation as a result of MMP activity contributes to the migration of bladder cancer cells and their extensive permeation of the bladder parenchym $(19,20)$. Previous studies have established that gelatinases (MMP-2 and MMP-9) play an important role in promoting the invasion and metastasis of cancer cells by degrading diffusely the basal membrane type IV collagen $(21,22)$. Higher levels of MMP-2 and MMP-9 have been found in bladder cancer tissue samples compared with normal bladder samples $(23,24)$. Kanayama et al $(25)$ indicated that the mRNA expression of MMP-2 and MMP-9 in muscular invasive bladder cancers was significantly higher than that in noninvasive tumors. The results of the present study suggest that afatinib treatment downregulated the expression of MMP-2 and MMP-9. Therefore, the present study indicates that afatinib is able to inhibit the invasion of T24 bladder cancer cells.

The PI3K/Akt (lipid kinase PI3K) and MAPK/ERK pathways, two important intracellular mediators of the EGFR signaling network, play an important role in the transmission of cell signals to the cell nucleus, where they control the expression of genes that regulate cell migration, proliferation, differentiation, apoptosis and cell invasion (26). It has been well established that aberration of the EGFR network plays a crucial role in the development of cancers, including non-small cell lung cancer, breast cancer and head and neck squamous cell carcinoma (27). Hyperactivation of EGFR pathway signaling leads to the overexpression of EGFR/HER-2, which increases the proliferation of cancer cells and reduced apoptosis (6). Akt, a serine-threonine kinase that is a major effector of PI3K, regulating cancer cellular growth, apoptosis and proliferation (28). Akt is widely activated in many cancers including bladder cancer (29). Data from the present study demonstrated that afatinib treatment resulted in significant inhibition of p-Akt in the T24 bladder cancer cell line. As Akt is a downstream target of PI3K, the observed inhibition of Akt phosphorylation indicated that afatinib treatment could lead to downregulation of the PI3K/Akt signaling pathway. The MAPK/ERK signaling pathway is a receptor tyrosine kinase mediated signaling pathway that regulates numerous biological processes such as angiogenesis, survival, proliferation, migration and the cell cycle by impacting the downstream activity of ERK (30-32). Constitutive activation of the MAPK/ERK signaling pathway leads to aberrant cellular proliferation, repressive apoptosis and the development of drug resistance $(32,33)$. The observations of the present study demonstrated that afatinib treatment resulted in significant inhibition of p-ERK1/2 in the T24 bladder cancer cell line, while no significant difference existed in t-ERK1/2 levels. As ERK $1 / 2$ is a downstream target of the MAPK/ERK signaling pathway, the observed inhibition of ERK1/2 phosphorylation indicated that afatinib treatment inhibited the MAPK/ERK signaling pathway. In this study, the reason why the PI3K/Akt and MAPK/ERK pathways are inhibited by afatinib treatment is not clear. It is hypothesized that this may be attributed to afatinib being a highly selective, irreversible inhibitor of EGFR and HER-2. In a future study, the correlation between afatinib and EGFR/HER-2 expression levels in bladder cancer should be investigated. Based on the above analysis, the results of the present study suggest that afatinib may inhibit proliferation and invasion of the T24 bladder cancer cell line and promote its apoptosis by inhibiting the PI3K/Akt and MAPK/ERK signaling pathways. Additional studies are required to further explore and elucidate the mechanism by which afatinib affects intracellular signal transduction in the T24 bladder cancer cell line.

In conclusion, the findings of the present study demonstrate that afatinib can inhibit the proliferation and invasion of T24 cells and induce their apoptosis by inhibiting the EGFR signaling network. However, further studies of the specific molecular mechanism involved in the afatinib-induced anticancer activity in bladder cancer are required.

\section{References}

1. Kaufman DS, Shipley WU and Feldman AS: Bladder cancer. Lancet 374: 239-249, 2009.

2. Jemal A, Bray F, Center MM, Ferlay J, Ward E and Forman D: Global cancer statistics. CA Cancer J Clin 61: 69-90, 2011.

3. Kwak C, Ku JH, Park JY, Lee E, Lee SE and Lee C: Initial tumor stage and grade as a predictive factor for recurrence in patients with stage T1 grade 3 bladder cancer. J Urol 171: 149-152, 2004.

4. Seshacharyulu P, Ponnusamy MP, Haridas D, Jain M, Ganti AK and Batra SK: Targeting the EGFR signaling pathway in cancer therapy. Expert Opin Ther Targets 16: 15-31, 2012.

5. Zhang H, Berezov A, Wang Q, et al: ErbB receptors: from oncogenes to targeted cancer therapies. J Clin Invest 117: 2051-2058, 2007.

6. Yarden Y and Sliwkowski MX: Untangling the ErbB signalling network. Nat Rev Mol Cell Biol 2: 127-137, 2001.

7. Li D, Ambrogio L, Shimamura T, et al: BIBW2992, an irreversible EGFR/HER2 inhibitor highly effective in preclinical lung cancer models. Oncogene 27: 4702-4711, 2008.

8. Harbeck N, Solca F and Gauler TC: Preclinical and clinical development of afatinib: a focus on breast cancer and squamous cell carcinoma of the head and neck. Future Oncol 10: 21-40, 2014.

9. Tsai YC, Yeh CH, Tzen KY, Ho PY, Tuan TF, Pu YS, Cheng AL, Cheng JC: Targeting epidermal growth factor receptor/human epidermal growth factor receptor 2 signalling pathway by a dual receptor tyrosine kinase inhibitor afatinib for radiosensitisation in murine bladder carcinoma. Eur J Cancer 49:1458-1466, 2013.

10. Quesnelle KM and Grandis JR: Dual kinase inhibition of EGFR and HER2 overcomes resistance to cetuximab in a novel in vivo model of acquired cetuximab resistance. Clinical cancer research 17: 5935-5944, 2011.

11. Greulich H, Kaplan B, Mertins P, Chen TH, Tanaka KE, Yun CH, Zhang X, Lee SH, Cho J, Ambrogio L et al: Functional analysis of receptor tyrosine kinase mutations in lung cancer identifies oncogenic extracellular domain mutations of ERBB2. Proc Natl Acad Sci USA 109: 14476-14481, 2012.

12. Cardillo MR, Castagna G, Memeo L, De Bernardinis E and Di Silverio F: Epidermal growth factor receptor, MUC-1 and MUC-2 in bladder cancer. J Exp Clin Cancer Res 19: 225-233, 2000.

13. Caner V, Turk NS, Duzcan F, et al: No strong association between HER-2/neu protein overexpression and gene amplification in high-grade invasive urothelial carcinomas. Pathol Oncol Res 14: 261-266, 2008.

14. Kiyoshima K, Oda Y, Kinukawa N, Naito S and Tsuneyoshi M: Overexpression of laminin-5 gamma2 chain and its prognostic significance in urothelial carcinoma of urinary bladder: association with expression of cyclooxygenase 2 , epidermal growth factor receptor [corrected] and human epidermal growth factor receptor [corrected] 2. Hum Pathol 36: 522-530, 2005.

15. Yang J, Liu X, Bhalla K, et al: Prevention of apoptosis by Bcl-2. release of cytochrome $\mathrm{c}$ from mitochondria blocked. Science 275: 1129-1132, 1997.

16. Lee DH, Ha JH, Kim Y, et al: A conserved mechanism for binding of p53 DNA-binding domain and anti-apoptotic Bcl-2 family proteins. Mol Cells 37: 264-269, 2014. 
17. OltvaiZN, Milliman CL and Korsmeyer SJ: Bcl-2 heterodimerizes in vivo with a conserved homolog, Bax, that accelerates programmed cell death. Cell 74: 609-619, 1993.

18. Kessenbrock K, Plaks V and Werb Z: Matrix metalloproteinases: regulators of the tumor microenvironment. Cell 141: 52-67, 2010

19. Choi YD, Cho NH, Ahn HS, Cho KS, Cho SY and Yang WJ: Matrix metalloproteinase expression in the recurrence of superficial low grade bladder transitional cell carcinoma. J Urol 177: 1174-1178, 2007.

20. Di Carlo A, Terracciano D, Mariano A and Macchia V: Urinary gelatinase activities (matrix metalloproteinases 2 and 9) in human bladder tumors. Oncol Rep 15: 1321-1326, 2006.

21. Chambers AF and Matrisian LM: Changing views of the role of matrix metalloproteinases in metastasis. J Natl Cancer Inst 89: 1260-1270, 1997.

22. Stamenkovic I: Matrix metalloproteinases in tumor invasion and metastasis. Semin Cancer Biol 10: 415-433, 2000.

23. Kanayama H, Yokota K, Kurokawa Y, Murakami Y, Nishitani M and Kagawa S: Prognostic values of matrix metalloproteinase-2 and tissue inhibitor of metalloproteinase- 2 expression in bladder cancer. Cancer 82: 1359-1366, 1998.

24. Davies B, Waxman J, Wasan H, et al: Levels of matrix metalloproteases in bladder cancer correlate with tumor grade and invasion. Cancer Res 53: 5365-5369, 1993.

25. Kanayama H: Matrix metalloproteinases and bladder cancer. J Med Invest 48: 31-43, 2001.
26. Brzezianska E and Pastuszak-Lewandoska D: A minireview: the role of MAPK/ERK and PI3K/Akt pathways in thyroid follicular cell-derived neoplasm. Front Biosci (Landmark Ed) 16: 422-439, 2011.

27. Nicholson RI, Gee JM and Harper ME: EGFR and cancer prognosis. Eur J Cancer 37 (Suppl 4): S9-S15, 2001.

28. Engelman JA: Targeting PI3K signalling in cancer: opportunities, challenges and limitations. Nat Rev Cancer 9: $550-562,2009$

29. Wu X, Obata T, Khan Q, Highshaw RA, De Vere White R and Sweeney C: The phosphatidylinositol-3 kinase pathway regulates bladder cancer cell invasion. BJU Int 93: 143-150, 2004.

30. Chang L and Karin M: Mammalian MAP kinase signalling cascades. Nature 410: 37-40, 2001

31. Akinleye A, Furqan M, Mukhi N, Ravella P and Liu D: MEK and the inhibitors: From bench to bedside. J Hematol Oncol 6: 27, 2013.

32. Friday BB and Adjei AA: Advances in targeting the Ras/Raf/MEK/Erk mitogen-activated protein kinase cascade with MEK inhibitors for cancer therapy. Clin Cancer Res 14: 342-346, 2008

33. McCubrey JA, Steelman LS, Chappell WH, et al: Ras/Raf/MEK/ERK and PI3K/PTEN/Akt/mTOR cascade inhibitors: how mutations can result in therapy resistance and how to overcome resistance. Oncotarget 3: 1068-1111, 2012. 